\title{
Curriculum design for pediatric radiology in Ethiopia
}

\author{
Kieran Walsh
}

Received: 27 May 2014 / Accepted: 16 June 2014 / Published online: 23 July 2014

(C) Springer-Verlag Berlin Heidelberg 2014

Sir,

Darge et al. [1] have presented an insightful view into the current state of play with regard to the practice of pediatric radiology and education in pediatric radiology in Ethiopia. Despite having a sizeable and growing population, Ethiopia has no pediatric radiologists. The various stakeholders involved in improving this situation should be praised for their efforts; however it is worth considering what strategic foundations Ethiopia could put in place to ensure that improvements are long-lasting.

There are certainly lots of activities in pediatric radiology training - however it is surprising that there was no mention of curriculum in the article. A curriculum is the cornerstone of any medical education intervention and so a curriculum in pediatric radiology should be developed for Ethiopia. The curriculum should ideally be based on the learning needs of the trainees, which in turn should be based on the needs of Ethiopia's people. After curriculum design would come curriculum provision, and this would need to be in forms that are accessible to the trainees. Another vital component is the assessment framework. Trainees should ultimately learn what comes up in their postgraduate exams, so it is vital to ensure that the content and standards of these exams are consistent with the real-life problems that trainees would face in Ethiopia. Results in the exams would be a means of delivering feedback to the trainees and driving quality improvement in the training program. This vision is ambitious and yet countries that are smaller than Ethiopia have fully functioning training programs that are delivering adequate numbers of high-quality trained specialists that can meet patient needs.

Last, as the authors correctly suggest there will be other pediatric specialties and other pediatric training program for example in surgery - and integration of content among programs would likely lead to both improved effectiveness and efficiency.

Conflicts of interest None

\section{References}

1. Darge K, Gorfu Y, Jaramillo D (2014) Ethiopia: who to educate, how to educate and what to teach. Pediatr Radiol 44:642

\footnotetext{
K. Walsh $(\bowtie)$

British Medical Journal Learning, British Medical Journal Group, BMA House, Tavistock Square, London WC1H 9JR, UK

e-mail: kmwalsh@bmjgroup.com
} 